\title{
Big Pharma and Big Medicine in the Global Environment
}

\author{
Anne E. Figert \\ Loyola University Chicago, afigert@luc.edu
}

Susan E. Bell

Bowdoin College

Follow this and additional works at: https://ecommons.luc.edu/soc_facpubs

Part of the Pharmacoeconomics and Pharmaceutical Economics Commons, and the Sociology Commons

\section{Author Manuscript}

This is a pre-publication author manuscript of the final, published article.

\section{Recommended Citation}

Figert, Anne E. and Bell, Susan E.. Big Pharma and Big Medicine in the Global Environment. Routledge Handbook of Science, Technology, and Society, , : , 2014. Retrieved from Loyola eCommons, Sociology: Faculty Publications and Other Works,

This Book Chapter is brought to you for free and open access by the Faculty Publications and Other Works by Department at Loyola eCommons. It has been accepted for inclusion in Sociology: Faculty Publications and Other Works by an authorized administrator of Loyola eCommons. For more information, please contact ecommons@luc.edu.

\section{(c) $(\ominus \ominus$}

This work is licensed under a Creative Commons Attribution-Noncommercial-No Derivative Works 3.0 License.

(C) Taylor \& Francis 2014 
Big Pharma and Big Medicine in the Global Environment

Anne E. Figert (Loyola University Chicago) and Susan E. Bell (Bowdoin College)

Forthcoming in the

Routledge Handbook of Science, Technology and Society

Daniel Kleinman

and

Kelly Moore (editors)

Draft 07/17/2013

Please do not quote from without the permission of the authors. 


\section{Introduction}

In previous work we argued that sociologists need to expand our thinking about pharmaceuticalization, the process of understanding and/or treating social, behavioral, or bodily conditions with pharmaceuticals. The majority of sociological scholarship has investigated pharmaceuticalization as a primarily Western process and conceptualized it in modern terms (Bell and Figert 2010, 2012a, 2012b). In our view, the work of anthropologists and science and technology studies (STS) scholars who decenter the West as the starting point for research opens up new avenues for understanding the global dynamics of pharmaceuticalization. We have also argued in favor of adopting a postmodern theoretical lens which allows us to understand pharmaceuticalization both as a strategy of enhancement by individuals in resource-rich societies and as an exercise of power in resource-poor societies and to bring to light its multiple, multidirectional and at times apparently contradictory effects.

In this chapter we expand upon our previous work and focus on one essential part of the pharmaceuticalization process: global clinical trials and related ethical and research standards. We also consider the role of global clinical trials in reducing public health strategies from a broad array of disease prevention efforts to one seeking to improve the health of populations with pharmaceuticals. The issues we explore center upon the key research and ethical standards for global pharmaceutical development. We define, review and problematize the concept of ethical variability and show how it simultaneously upholds and disrupts Western ethical guidelines for human subjects research. In doing so, we show how global clinical trials contribute to the further pharmaceuticalization of public health worldwide with major implications for people’s lives globally. The degree 
and scope of how people interact with pharmaceuticals throughout the world is uneven, because pharmaceuticalization and global clinical trials map onto global patterns of inequality. Some human bodies serve as research subjects whereas some bodies are pharmaceutical sales targets. Whereas some people in some areas of the world are (over)pharmaceuticalized, other people are (under)pharmaceuticalized. We conclude the chapter with a discussion of how and why STS perspectives on harmonization and variability in ethical and research standards shed light on the study of pharmaceuticalization and more broadly on the global dynamics of health inequality.

\section{Conceptual Framing: Medicalization, Biomedicalization and Pharmaceuticalization}

Because studies of pharmaceuticalization have taken shape alongside the development of scholarship about medicalization and biomedicalization, we begin with a brief overview of these fields. The concept of medicalization was introduced to the medical sociology field in the 1970s to understand and look critically at "the involvement of medicine in the management of society" (Zola 1972: 488). Medicalization is now ubiquitously used in the social and medical sciences and has successfully moved into popular culture. One of the most influential definitions of medicalization comes from US sociologist Peter Conrad (2005:3) who declares that the essential meaning of the term is "defining a problem in medical terms, usually as an illness or disorder, or using a medical intervention to treat it" [emphasis in the original]. Medicalization explains a process of medical expansion in a modern society. It makes sense of how and why more and more conditions are defined and treated medically and increasingly pharmaceutically.

Current medicalization scholarship has refocused our analytic gaze from the power and authority of the medical profession to consider the active participation of 
individual patient/consumer/users individually and collectively in medicalization processes (Brown and Zavestoski 2005; Crossley 2006), resistance to pharmaceuticals (Figert 2011; Williams et al. 2011), and the use of medical prescription drugs for nonmedical purposes (Williams, Seale et al. 2008). It has also explored new “engines” of medicalization including the pharmaceutical industry (Conrad 2005) and technoscience (Clarke et al. 2003). Although medicalization is a capacious concept, it cannot fully capture the contemporary global dynamics of pharmaceuticals and technoscience. Thus scholars have introduced the concepts of biomedicalization, pharmaceuticalization, and pharmaceuticalization of public health, which are often more effective than medicalization alone in analyzing the nuances and complexities of the development, testing, expansion and distribution of pharmaceuticals in the world today (see Abraham and Davis (2014) in this volume and Bell and Figert 2012a for a more extensive discussion).

Whereas the process of medicalization can be conceived of in modern terms of engineering, control, and rationalization, the process of biomedicalization can be conceived of in postmodern terms of networks, spirals, and complexity. Understanding both the definition and effects of biomedicalization helps to make sense of how and why more and more conditions are defined and treated medically and pharmaceutically in the 21st century. Biomedicalization, as established by Clarke and her colleagues, is a concept and analytic tool that captures "the increasingly complex, multisited, multidirectional processes of medicalization that today are being both extended and reconstituted through the emergent social forms and practices of a highly and increasingly technoscientific biomedicine” (Clarke et al 2003, 162). One example of this is the application of screening 
technologies using molecular biomarkers that constitute new categories of people at risk and new opportunities for biomedical surveillance and intervention as well as selfmonitoring and regimens of behavior change (Shostak 2010).

Although feminist scholars and activists in Women’s Health Movements have looked critically at the development of the birth control pill and other reproductive technologies since the 1970s and social scientists have studied pharmaceuticals and the pharmaceutical industry for many years (e.g., Boston Women’s Health Book Collective 1973; Hartmann 1987; Gabe and Bury 1988), pharmaceuticalization as a unique term was introduced by anthropologists (Nichter 1989). A broadly accepted definition of pharmaceuticalization by sociologist John Abraham is "the process by which social, behavioral or bodily conditions are treated, or deemed to be in need of treatment/intervention, with pharmaceuticals by doctors, patients, or both” (Abraham 2010a: 290). There are complex forces generating the expansion of pharmaceuticalization: Big Pharma’s industry control over the science underpinning drug development and testing, skillful use of marketing, and “disease mongering;” physicians as prescribers, gatekeepers, and "developers of new medicines often in alliance with the industry;” affluent publics in consumer-oriented societies who use information technology and become "expert patients;” and governments and insurance companies (for a discussion of these forces see the chapter by Abraham and Davis in this volume).

Pharmaceuticalization scholarship builds on and has explicit ties with medicalization scholarship, but scholars generally agree that pharmaceuticalization can occur without medicalization, and vice versa. Studies of the pharmaceutical process, like those of the medicalization process, typically do so from the perspective of modern social 
theory. They draw inspiration and logic from the natural sciences, adopt an engineering mentality (Lock 2004), trace the drug development and approval process in terms of “countervailing powers” (Busfield 2006), and identify pharmaceuticalization as a search for control of behavioral, bodily, or social conditions (Bell and Figert 2012a).

In our work, we show that current research in anthropology provides a useful layer of understanding pharmaceuticalization (Bell and Figert 2012a). Whereas sociologists primarily study pharmaceuticalization by focusing upon power, economics and treatments in the West and the dynamics of the largest pharmaceutical companies (often called Big Pharma) and high-income nation states, anthropologists focus primarily upon the issues of pharmaceuticals in low or middle-income countries where the political economic systems are often post-colonial or post-communist. This focus has allowed anthropologists to conceptualize pharmaceuticalization differently and to examine political, economic and organizational dynamics that are less visible in the studies by sociologists.

The pharmaceuticalization of public health as outlined by Biehl and others suggests that there is both a political and an economic rationality to cutting back on disease prevention efforts in favor of a national pharmaceutical distribution policy (Biehl 2007, Whitmarsh, 2008). From a neoliberal state perspective, it is cheaper and more efficient to diagnose and treat diseases pharmaceutically than to prevent them through traditional public health measures. The process of pharmaceuticalization and the policy of the pharmaceuticalization of public health are key factors in the expansion of the use of pharmaceuticals to treat medical and social problems. These two "strands" of pharmaceuticalization theory and research shed light on the uneven and unequal global 
processes of pharmaceuticalization. Thus, in the global North, pharmaceuticalization is primarily about expanding social and behavioral diagnostic categories and diagnoses, while in the global South, pharmaceuticalization is primarily about expanding access to medicines and public health or of increasing testing sites for pharmaceutical clinical trials. In the global South, citizens and nongovernmental organizations (NGOs) - often in response to the HIV/AIDS epidemic - have mobilized and demanded access to certain drugs or treatments.

The pharmaceuticalization of public health scholarship also brings a postmodern framework to understanding pharmaceuticals today. We use the term "postmodernity" to refer to society based on information technology and characterized by interaction, contingency, fragmentation, volatility, and hybridity. In postmodern society, boundaries are blurred, such as between public/private, government/corporation, expert/lay, human/animal, and human/machine. Postmodern theory assumes that the political economic, cultural, organizational, and technoscientific trends and processes of pharmaceuticalization are complex and mutually constituted. The pharmaceuticalization of public health is manifest in macrostructural changes as well as in new personal identities, subjectivities, and configurations by seeking to connect global dynamics among states, non-governmental organizations (NGOs), pharmaceutical companies, and local communities (see Petryna et al. 2006; Clarke et al. 2010; Bell and Figert 2012a).

Much work remains to be done in exploring how pharmaceuticalization works globally, and we must recalibrate the balance between studies of the global North and global South (e.g., Brazil [Biehl 2006, 2007], Barbados [Whitmarsh 2008], India [Sunder Rajan 2007, 2012], Thailand, Uganda and South Africa [Petty and Heimer 2011], and 
Poland [Petryna 2009]). The pharmaceuticalization of public health can be used to make sense of dynamics where states with less power and wealth define free access to pharmaceuticals as rights of citizenship (and a new subjectivity, pharmaceutical citizenship). It can make visible ways that pharmaceuticalization can contribute to the creation of new democratic tools for individuals, activist groups, and states. For example, participation in clinical trials of pharmaceuticals can be a strategy to gain access to drug treatments and medical care and accomplish what people believe to be in their best economic and medical interests. For societies with few resources, pharmaceuticalization can be a strategy for realizing the rights of citizens and improving population health. Yet defining rights of citizenship as access to pharmaceuticals creates new possibilities for entering into the grip of biomedical power, forecloses other approaches to improving population health and wellbeing, and contributes to the pharmaceuticalization of public health.

\section{Standardization and Global Clinical Trials}

In this section, we show how the global expansion of clinical trials and the global standardization of research procedures and ethics foster pharmaceuticalization and the pharmaceuticalization of public health. Standardization is the process of constructing uniformities across space and time. These uniformities, created by multiple historically situated actors, are expressed in standards (Timmermans and Berg 2003). The standards, in turn, coordinate people and things in "new configurations" (Timmermans and Epstein 2010: 83). The standardization of both research procedures and ethics has facilitated the proliferation of global clinical trials, the portability of results and the global expansion of markets. These standards are expressed in and enforced by international organizations 
(e.g., the International Conference on Harmonization of Technical Requirements for Registration of Pharmaceuticals for Human Use [ICH], the Agreement on Trade Related Aspects of Intellectual Property [TRIPS]), regulatory agents of the state (e.g., US Food and Drug Administration, Drug Controller-General of India), professional governance (e.g., the Declaration of Helsinki), and codes and formal laws (e.g., The Nuremberg Code, The Belmont Report). At the same time the development of global clinical trials has coordinated people and things into new configurations (e.g., “Contract Research Organizations”), and subjectivities (e.g., “treatment naïve populations,” "treatment saturated populations” discussed later in this chapter). Increasingly, clinical pharmaceutical trials have been privatized by the development of a contract research industry (Fisher 2006, 2009).

While not all clinical trials are conducted with pharmaceuticals, many studies by anthropologists and sociologists focus on the expansion of global clinical pharmaceutical trials as primary components of pharmaceuticalization (e.g., Petryna, Lakoff and Kleinman 2006, Dumit 2012a, Williams, Gabe and Davis 2008). In 2006, more than 2.4 million Americans participated in clinical trials (Dumit 2012a:18). Since the 1990s, the number of international subjects involved in clinical trials - including pharmaceutical trials - has grown substantially, from 4000 in 1995 to 400,000 in 1999 (Petryna 2006:189). Until recently, much of the pharmaceutical and clinical research was conducted in the US and Western Europe, but today it is likely to be conducted elsewhere. During February 2013, 29,623 clinical trials were actively recruiting study participants, and almost half of the trials (49\%) were seeking subjects exclusively outside the United States (http://www.clinicaltrials.gov/ Feb. 11, 2013). 
There are multiple, multidirectional reasons that clinical trials are pushed and pulled globally. The time between first identification of an active agent with therapeutic potential and formal approval for marketing is $10-15$ years and each new drug costs $\$ 897$ million to develop (Busfield 2006; Petryna et al. 2006: 11). ${ }^{1}$ Developing countries in particular are likely to have fewer regulations and a looser regulatory apparatus for enforcing ethical and research standards. They provide cheaper labor and lower infrastructure costs, reducing overall expenses of clinical trials by 30 to 50 percent (Sunder Rajan 2007: 72). In addition they reduce the time line for clinical testing by accelerating subject recruitment and improving the likelihood of showing drug effectiveness because their populations are more likely to be pharmaceutically or treatment naïve, that is to have little or no previous access to pharmaceuticals and no background medications at the time of the trial that might confound results.

Clinical trials are pushed and pulled globally to reduce time and expense both because in the US and Western Europe patients and potential human subjects are increasingly skeptical of drug trials and because patients and physicians in Eastern Europe, Eurasia and the global South need the resources that pharmaceutical companies offer. The global expansion of clinical trials opens the possibility for individuals and communities to gain access to medicines otherwise unavailable to them (Biehl 2006, Nguyen 2005). The use of these pharmaceutically naïve subjects "creates efficient results, free of statistical noise” (Petryna 2007: 37).

\section{Standardizing global research procedures}


The standardization of clinical trials and research procedures and the actors involved in this standardization in the 1990s played an important role in the expansion of global clinical trials and pharmaceuticals. Global technical standards specifically for pharmaceutical research began to be institutionalized in the 1990s, exemplified by the development of Contract Research Organizations (CROs) and the International Conference on Harmonization (ICH). CROs create mobile clinical trial environments and trial results. CROs are private, for profit companies that implement and manage global clinical trials for large multinational pharmaceutical companies. Fisher (2009) reports that over 75 percent of clinical drug trials in the US are now conducted in the private sector. Since the US is the largest pharmaceutical market in the world and by some recent estimates Big Pharma makes two-thirds of its profits in the United States, the process for pharmaceutical testing in the US and its legitimation by the US Federal Food and Drug Administration (FDA) guide how pharmaceutical companies conduct clinical trials outside as well as inside the US (Harris 2013). There are four distinct phases of pharmaceutical testing for approval by the FDA. Each phase is designed to build upon the others and requires increasing numbers of participants. If a drug is determined to be safe in a small group of healthy volunteers (Phase 1with 20-80 participants) and effective in treating the targeted condition (Phase 2 with 100-300 participants), the drug will move to Phase 3 which is characterized by a large group of participants (usually between 1,000 and 3,000 people) to confirm the effectiveness and scrutinize any possible side effects. In some cases, a Phase 4 (also called "post-marketing") trial will be conducted. This phase is primarily observational and is non-experimental and may explore new uses or dosages, or use in new populations. 
CROs work in and serve as the "middlemen” or service providers (see Fisher, 2009). In primarily low- and middle- income countries, CROs identify research sites, clinics, practitioners and recruit human subjects. International CRO's are important in the process of moving a drug from Phase 2 to Phase 3, because of the need for large numbers of participants. Their main source of revenue comes from conducting clinical trials efficiently and cost effectively (Petryna 2006: 38). CROs also help to ensure that clinical research complies with accepted technical standards and national and international ethical guidelines and thereby makes "data from various international sites portable to and usable within the US drug approval process” (Petryna 2011:307).

From 1992 to 2004 the CRO market grew from $\$ 1$ billion to $\$ 7$ billion and by 2004 there were more than 1000 CROs worldwide. A recent survey of CROs found that pharmaceutical companies outsourced a wide variety of functions to CRS from design to site selection, study conduct, and medical writing (Getz and Vogel 2009). Sunder Rajan (2007) highlights the role that consulting firms, such as A.T. Kearney, play in helping Big Pharma find international testing sites. Kearney developed an attractiveness index for clinical trials (calculated by evaluating patient availability, cost efficiency, relevant expertise, regulatory conditions and national infrastructure) and determined that the most favorable pharmaceutical testing sites were China, India and Russia (Bailey et al. 2009: 57). Sunder Rajan (2012: 332) points out that unlike the pharmaceutical companies for which the locus of value lies in the valorized expansion of health, the locus of value for CROs is the valorized expansion of pharmaceutical clinical trials.

The development of the CRO industry occurred concurrently with and was fostered by the introduction of guidelines for clinical trials established in 1990 by the 
International Conference on Harmonization (ICH). The ICH was the product of international pharmaceutical regulators from the US, the European Union, Japan and the pharmaceutical industry (see http://www.ich.org/about/vision.html). In effect, the ICH established uniform research and technical requirements and standards such as randomized controlled trials (RCT) - in which subjects are randomly assigned to either a treatment group or a control group - in drug testing. At first the use of these standards “made clinical data from international research sites transferable and acceptable to regulatory bodies in” the major markets of Europe, Japan, and the United States (Petryna 2007: 30). Since 2007 the ICH has opened up its process and expanded its reach beyond these major markets. For example, representatives of drug regulatory agencies from Australia, Brazil, China, Chinese Taipei, Russia, India, Singapore, and South Korea have been invited to attend the ICH (http://www.ich.org/). Together CROs and the ICH construct uniform standards for global clinical trials across time and space.

\section{Standardizing global research ethics and ethical variability}

The successful expansion of global pharmaceutical research depends on adhering to certain established international ethical standards. At the same time, global expansion fosters the transformation of these same ethical standards. Since the 1980s, the global dynamics of the pharmaceutical industry have played "an important role in shaping contexts in which ethical norms and delineations of human subjects are changing” (Petryna 2006: 34). In the common narrative of research ethics, ethical standards for clinical trials can be traced to the Nuremberg Code (1947) and the Declaration of Helsinki (1964), which provide both a moral framework and an explanation for how and 
why human subjects need and are protected in ordinary scientific and medical practice (Hoeyer 2009). In this section we argue that recent revisions to the Declaration of Helsinki have created a new configuration of unethical trials, that global ethical standards often produce the impetus, justification and tools for turning healthy populations into experimental subjects, and that a modernist frame of understanding cannot account for these effects.

There was no international statement differentiating between legal and illegal human experimentation until the Nuremberg Code (a set of ten points related to human experimentation targeting Nazi doctors and scientists) was established in 1947 during the World War II war crimes tribunal. The voluntary consent of the prospective human subject is the bedrock of the Nuremberg Code. The Code requires that all unnecessary physical and mental suffering should be avoided, the degree of risk should never exceed the benefit which may derive from the tested drug or treatment and the research should be conducted by scientifically qualified persons. ${ }^{2}$ The Nuremberg Code continues to serve as a "blueprint for today's principles that ensure the rights of subjects in medical research” (Shuster 1997: 1436) although some scholars have convincingly argued that it was frequently ignored by scientists and physicians because it was really only for Nazi "barbarians" and not everyday scientists and physicians (Katz, 1992, Rothman, 1991 and Hoeyer, 2013).

The Declaration of Helsinki, ${ }^{3}$ established in 1964 by the World Medical Association, seeks to guide physicians in research with human subjects, and leaves intact physicians' civil, criminal and ethical responsibilities under the laws of their own countries. Katz (1992) argues that in contrast to the Nuremberg Code, in the Declaration 
of Helsinki concerns over the advancement of science began to overshadow concerns over the integrity of person. The Declaration has been amended regularly since 1964 but the most controversial amendments have to do with the issues of the use of placebos, international testing, informed consent, and access to treatment at a trial's conclusion. Effectively, by establishing that placebo trials are acceptable only when no proven treatment already exists, the 1996 and 2000 revisions to the Declaration created a new configuration of unethical clinical trials in the US and other countries. In the 1996 revision to the Declaration, the idea of a placebo, an inert substance or one containing no medication, is introduced for the first time:

In any medical study, every patient - including those of a control group, if any should be assured of the best proven diagnostic and therapeutic method. This does not exclude the use of inert placebo in studies where no proven diagnostic or therapeutic method exists (as quoted in Carlson et al 2004: 698).

In contrast, the 2000 revision to this paragraph reads:

The benefits, risks, burdens and effectiveness of a new method should be tested against those of the best current prophylactic, diagnostic, and therapeutic methods. This does not exclude the use of placebo, or no treatment, in studies where no proven prophylactic, diagnostic or therapeutic method exists (as quoted in Carlson et al. 2004: 700, emphasis in original).

The US and the FDA have not recognized these recent amendments to the Declaration regarding the preference for testing new pharmaceuticals and vaccines against the best current methods instead of against a placebo, arguing that this would inhibit the development of good science and efficacious drugs (see Wolinsky 2006). Pharmaceutical 
trials funded by the US government and its agencies continue to use placebo testing throughout the world.

International ethical guidelines for research involving human subjects - such as the 1996 and 2000 revisions to the Declaration of Helsinki - are being recast along with the movement of clinical trials globally. Revisions concerning the use of placebos in pharmaceutical research can be traced a growing concern about international studies of maternal-fetal HIV transmission in developing countries (Carlson et al., 2004). In an article published in the New England Journal of Medicine, Lurie and Wolfe (1997) questioned why studies outside the US sponsored by a US government agency, the National Institutes of Health, used a placebo design even though there was already a known and effective treatment to prevent maternal-fetal HIV transmission available in the US. Supporters of the study design and implementation argued that "local cultural variables and deteriorated health services” made placebos acceptable and that it would be a "paternalistic imposition” for the US to determine the appropriate design of research in regions of such poverty (Petryna 2007: 28-29). Similarly, local and national authorities in these regions argued that they should determine research conduct and treatment distribution.

As clinical pharmaceutical trials have become globalized, STS scholars and others have examined how enacting ethical standards internationally takes place. Petryna (2007) argues that "ethical variability" - the creation of local standards to recruit human subjects for clinical and pharmaceutical research - produces the conditions for the exploitation of “Third World subjects.” Ethical variability legitimates the modification of ethical standards according to the local contexts of clinical trials. It has evolved as a tactic for 
weighing immediate health benefits or outcomes against protection and safety considerations and not as a strategy for being sensitive to those persons asked to enroll in clinical pharmaceutical trials (Petryna 2007; Farmer and Campos 2004).

More generally, participants and clinics always adjust and use workarounds in implementing ethical standards. Drawing from their study of HIV treatment and clinical trials in the global North (2 US clinics) and South (one each in Thailand, Uganda and South Africa), Heimer and colleagues show that in all clinics, both North and South, "neither research subjects nor the recruitment and consent process actually live up to the ethical ideals as embodied in the institutions of informed consent” (Heimer, 2012: 24). When researchers or state agencies try to implement any local or global standards, it is inevitable that the practices will include workarounds and adjustments.

Social scientists have observed repeatedly that the Nuremberg Code, Declaration of Helsinki, and similar ethical standards for research assume autonomy and choice of the individual "and downplay social and economic constraints on individual agency" (Marshall and Koenig 2004: 255; see also Fisher, 2009). The result is that global ethical standards often provide the impetus, justification and tools for turning healthy populations into experimental subjects. As Angell warned in 1997:

Research in the Third World looks relatively attractive as it becomes better funded and regulations at home become more restrictive. Despite the existence of codes requiring that human subjects receive at least the same protection abroad as at home, they are still honored partly in the breach. The fact remains that many studies are done in the Third World that simply could not be done in the countries sponsoring the work. Clinical trials have become a big business, with many of the 
same imperatives....Those of us in the research community need to redouble our commitment to the highest ethical standards, no matter where the research is conducted, and sponsoring agencies need to enforce those standards, not undercut them (1997: 849).

To summarize, on the one hand the construction of a universal standard or ethical code of conduct for pharmaceutical clinical trials appears to be "good" or "just” because it is sensitive to imbalances of power and money. This interpretation would work within a modernist framework. On the other hand, treating all people as equal in a world characterized by inequality effectively serves to reinforce that inequality. The harmonization of ethical codes or standards for global clinical trials obfuscates the reproduction and exacerbation of global inequality. Furthermore all global standards are practiced and implemented locally and thus entail local workarounds and adjustments in the field. The modernist frame, dominant in sociological accounts of pharmaceuticalization, cannot account for all of these practices and effects. A postmodern framework for understanding global clinical pharmaceutical trials helps the analyst move away from an either/or framing to understand that ethical variability is not always bad and standardization is not always good. Both variability and, as we discuss next, standardization, can produce different outcomes depending upon local settings and histories.

\section{Disruptions to Standardization?}

In this section we show how standard sociological and modernist conceptual frameworks for understanding pharmaceuticalization are simply insufficient to explain the expansion of clinical trials to the Global South or how in some respects those in low 
resourced countries benefit more by participation in these trials than those in high resourced countries. We address the question of how an understanding of standards and rules sheds light on the conceptualization and processes of global pharmaceuticalization and the pharmaceuticalization of public health, and we use work on the expansion of pharmaceutical clinical trials in India by Sunder Rajan to illustrate our argument (Sunder Rajan 2005, 2007, 2012).

As discussed above, with the expansion of the number of clinical trials, the need for human subjects increases, and trials are more and more likely to be conducted in the global South with the goal of producing portable results. One reason given for this is that these countries are seen as having fewer regulations and a looser regulatory apparatus (Petryna, 2009). Since the 1990s, India has become incorporated into the globalized drug development sector. In his study of global pharmaceutical economies, Sunder Rajan (2007, 2012) contests the assumptions that ethical standards are "stricter" in the West. In 2005 India converted its guidelines for informed consent into laws (Schedule Y) and is now the only country in the world "where the violation of good clinical practice is a criminal rather than a civil offence” (Sunder Rajan 2007: 74). Indeed, Schedule Y focuses on ways of insuring informed consent from subjects who are poor and illiterate. In many ways, this means that local ethical standards in India are especially tight, and global harmonization could diminish the possibility of developing local standards such as these. On the surface, the informed consent process in India provides potential experimental subjects with the choice to freely participate or not participate in clinical pharmaceutical trials. And yet, although subjects may freely give consent to participate in clinical trials, their access to pharmaceuticals ends along with the end of the trials. 
Experimental subjects are still exploited, or in Sunder Rajan’s terms “merely risked” because for this population, clinical experimentation is not linked to the benefit of subsequent therapeutic access.

The harmonization of ethical standards provides the conditions for continued global pharmaceutical and economic inequality. In India, the apparatus of clinical trials simultaneously accepts Western bioethics standards of informed consent and rigorously applies them so its research results can travel. At the same time, its population will bear the burden without the benefit of research results. In its careful attempt to adhere to global (universal) standards, India creates conditions for the exploitation of Indian bodies (and by implication of Third World subjects more generally) because of the real economic rewards and the potential for further inclusion in the global pharmaceutical economy.

In the US and most of the world, there is less attention to the ethics of how poverty and specific forms of indebtedness shape consent and decisions in pharmaceutically naïve populations ${ }^{4}$ or whether the burden of research is balanced with tangible therapeutic benefits after completion of trials (Fisher, 2009). Advocacy groups have learned to fight for access to pharmaceuticals for citizens in the global south (as they did successfully in Brazil) (see Biehl 2004, 2007) and for the importation of more affordable generic versions of medicines from foreign manufacturers, as Brazil, Argentina and South Africa have done for AIDS medicines (WHO Drug Information v. 19, no. 3 2005, Access to Medicines). ${ }^{5}$ One way that pharmaceutical companies respond to such activism and pressure is by providing therapeutic access through their compassionate use programs "which make the drugs tested in Phase 3 trials available to 
the sick volunteers for a fixed period of time after completion of the trial” (Sunder Rajan 2007: 79).

The dynamics of clinical pharmaceutical trials in India, Barbados and Brazil are representative of new forms of an international bioeconomy in which nations, the pharmaceutical industry and other corporate actors work to create global experimental sites. In this new phase of capitalism, clinical pharmaceutical trials establish places where experimental subject populations exchange human bodies for payment in the form of cash or access to treatment (Sunder Rajan 2006, Dumit, 2012a). In this context, the problem of the exploitation of third world "merely risked" subject populations is not the result of the harmonization of standards - either looser standards pulling clinical trials to the global South or tighter standards protecting experimental subjects in the global Southbut reflects the reorganization and reconceptualization of global capital in relation to "life itself” since the 1980s.

\section{New Configurations}

Although the global expansion of clinical trials works unevenly throughout the world, there is some evidence that in some respects physical sites of the new bioeconomy such as health or pharmaceutical clinics in "poor" countries benefit more from these trials than do clinics in "rich" countries. Thus, in a study of clinical trials in countries at varying levels of development - the US, South Africa, Thailand and Uganda - Petty and Heimer (2011) and Heimer (2012) show that global HIV research can be more beneficial to countries in the Global South than to the US. Clinics reconfigure their local practices of care and treatment to bring them in line with ICH standards: to produce accurate, complete, and verifiable study data and to ensure "that the rights and well-being of 
human subjects are protected” (Petty and Heimer 2011: 350). These reconfigurations include upgrading laboratory facilities to be able to do the complicated tests required by clinical trials and using laboratory equipment in study-specific ways to produce standardized results. The new configurations vary depending on clinics' existing resources, routines, and relationships. In poorer countries, where equipment is often in short supply funders often pay to improve laboratory facilities so clinics can participate in research (Petty and Heimer 2011: 342). Once laboratory facilities are upgraded, clinics in poorer countries can employ them in both research and treatment. However, because materials are less easily repaired, replenished, or replaced, "the overall effect of altering the material environment in poorer countries is likely to be modest unless the flow of funds is very stable” (Petty and Heimer 2001: 357). By contrast, in richer countries, research-provided technologies duplicate already available medical equipment and doing the research has a less beneficial effect.

Clinical pharmaceutical trial participation can also reshape the clinics in ways that smooth the way for their later adoption of clinical research findings. The everyday actions and results of introducing new jobs, technologies, and standard operating procedures for clinical trials is as important to changing medical practice as is the influence of subsequent research results. Petty and Heimer (2011) identified three types of practices that are changed in the doing of clinical research. The introduction of new research-mandated tools alters the material environment, the introduction of new and/or retrained staff reorganizes staff relationships in the clinics, and the adoption of research practices changes clinic priorities. In other words, conducting clinical research is not just a means of testing new treatments that subsequently change medical practice. The new 
routines for clinical trials change clinic practices so that new therapies will fit local conditions and can be translated into medical care (Petty and Heimer 2011). In the process of conducting clinical trials, standardization of actions and practices for doing the research reshapes the clinics and gives further agency and sometimes bargaining power to the clinic staff to advocate for their patients.

In reconfiguring their local practices in order to participate in global clinical trials, Petty and Heimer (2011) found that clinics in the US and the global South fostered a pharmaceutical approach to public health that ultimately necessitated and created reliance upon technoscience and biomedicine beyond money and supplies. More generally, participation in pharmaceutical clinical trials creates regimes of practice and enforces ways of thinking and action that focus on pharmaceutical solutions. It forecloses other ways of thinking about and treating public health problems. While providing certain kinds of benefits to resource poor countries, the pharmaceuticalization of public health projects (vaccines, pharmaceutical testing or treatments) excludes cheaper and more effective ways to treat the health of the general population. When clinics change how they work and think about the way to treat patients in adjusting to pharmaceutical trials, they narrow the gaze and focus to one that concludes pharmaceuticals are the ultimate solution to improving public health. This is especially problematic in states with fewer resources because it ultimately narrows the options to more technological and capital intensive solutions.

\section{Conclusion}

In this chapter we have argued that global research and ethical standards of pharmaceutical development - especially in global clinical trials-are institutionalized, 
disrupted and/or shaped by nation states and international bodies, local and global cultures, and multinational pharmaceutical firms. The standard pharmaceuticalization and modernist framework uses one of two possible narratives about why and how clinical trials and ethical practices have become standardized. In the first narrative, the institution of medicine in conjunction with international regulatory bodies successfully developed and adopted scientific and ethical frameworks for the conduct of clinical trials globally. The result is better, well-designed, portable, and ethical scientific research and pharmaceutical products. The second explanation suggests an alternative result, that global bodies are being exploited by the capitalistic expansion of pharmaceutical companies into the global South in the pursuit of cheaper trials and an undermedicalized surplus army of available bodies.

But neither of these modernist frames fully captures what is going on with global pharmaceutical trials. Ultimately, the outcomes of the clinical trial process internationally do not fit standard modernist narratives of either exploitation or the ethical advance of scientific research. A modern perspective on global clinical trials employs an either/or analysis. Global clinical trials can also be seen through a postmodern framework that captures the uneven and contradictory character of pharmaceutical trials occurring throughout the world. We show that bodies used in clinical trials may or may not ever benefit from pharmaceutical development and may or may not be exploited during and after the trials conclude. A postmodern perspective enables a more subtle analysis: pharmaceutical and clinical trial innovations are made possible by and at the same time foster major shifts in the global political economy. This ambiguity is especially apparent in the pharmaceuticalization process. Global pharmaceutical trials and ethical research 
standardization are complex, global, and multi-sited and involve remaking the technical, organizational, and institutional infrastructures of the life sciences and biomedicine. The pharmaceutical transformation of life and approach to public health is associated with a new, postmodern, era in medicine and society more broadly.

To support our argument, we analyzed two cases: Sunder Rajan’s study of clinical trials in India and Petty and Heimer's study of global clinical research in HIV clinics. Both of these cases explain how local circumstances help to make sense of pharmaceuticalization and the pharmaceuticalization of public health and both cases are better explained by a more postmodern than a modern frame. Sunder Rajan shows that the particular history of the pharmaceutical industry in India, Indian CROs, and labor exploitation, are explanatory "forces" that have led to India's desire to be a location for clinical trials. In spite of the fact that most Indians may not benefit directly from pharmaceutical research, some poor and illiterate Indians do gain access to clinical trials after informed consent is carefully administered to them. Using Sunder Rajan's case of India, we conclude that a modernist explanation of either economic exploitation or benefit does not go far enough.

In the second case we show that the global expansion of clinical trials works unevenly throughout the world and further that in some respects clinics in "poorer" countries benefit more from these trials than do clinics in "richer" countries. For example, Petty and Heimer document how an unintended consequence of participating in global clinical HIV trials for those in poor countries is the reconfiguration of their organizational and medical practices. An additional consequence is the pharmaceuticalization of public health even though it may be a more expensive strategy. Through their participation in 
clinical trials, clinics create a regulatory, clinical and institutional apparatus that fosters a pharmaceutical approach to HIV. As they write: “... the costs of new pharmaceuticals can easily overwhelm the healthcare systems of poor countries, when investing in the lower-end of healthcare would surely be wiser” (Petty and Heimer 2011: 357). Public health becomes pharmaceuticalized with significantly different procedures and consequences. The contradictions, reversals, and production of new subjectivities such as pharmaceutical citizenship or reconfigured clinics are better explained by a postmodern than a modern theory of pharmaceuticals.

Finally, both of these cases show that while in theory the call for global ethical research standards appears to be a modern and scientific way forward, in reality the implementation of these standards is not "standard" and not always beneficial to clinics and patients in poor countries. Clinics or countries encourage and produce "workarounds" in their efforts to conform to standards. Distinctions such as ethical variability versus standardization—and the modernist assumptions and interpretations of their effects--fail to capture some of the surprising ways in which standards and variability shape the experiences of people in very different parts of the world who are part of a global pharmaceutical system, and thus modernist approaches do not help us fully comprehend the dynamics of global health inequality. 


\section{References Cited}

Abraham, J. 2007. "Building on Sociological Understandings of the Pharmaceutical Industry or Reinventing the Wheel? Response to Joan Busfield's 'Pills, Power, People'." Sociology 41: 727-736.

—. 2010a. "The Sociological Concomitants of the Pharmaceutical Industry and Medications." In Handbook of Medical Sociology, edited by C. Bird, P. Conrad, A. M. Fremont, and S. Timmermans, 290-308. Nashville: Vanderbilt University Press.

—. 2010b. Pharmaceuticalization of society in context: theoretical, empirical and health dimensions. Sociology, 44(4), 603e622.

Angell, Marcia. 1997. "The ethics of clinical research in the Third World." New England Journal of Medicine-Unbound Volume 337.12 (1997): 847-849.

Bailey, W., C. Cruickshank, and N. Sharma. 2009. "Make Your Move: Taking Clinical Trials to the Best Location." In Executive Agenda, A. T. Kearney: A. T. Kearney. http://www.atkearney.com/ retrieved January 13, 2013, 56-62.

Bell, S. E. and A. E. Figert. 2010. "Gender and the Medicalization of Health Care " In Palgrave Handbook of Gender and Healthcare, edited by E. Kuhlmann and E. Annandale,107-122 City: Palgrave Macmillan.

Bell, S. E. and A. E. Figert. 2012a. "Medicalization and Pharmaceuticalization at the Intersections: Looking Backward, Sideways and Forward." Social Science \& Medicine 75: $775-783$.

Bell, S. E. and A. E. Figert. 2012b. "Starting to Turn Sideways to Move Forward in Medicalization and Pharmaceuticalization Studies: A Response to Williams et. al." Social 
Science \& Medicine 75: 2131-2133.

Biehl, J. 2004. "The Activist State: Global Pharmaceuticals, AIDS, and Citizenship in Brazil." Social Text 22: 105-132.

Biehl, J. 2006. "Pharmaceutical Governance." In Global Pharmaceuticals: Ethics, Markets, Practices, edited by A. Petryna, A. Lakoff, and A. Kleinman, 206-239. Durham: Duke University Press.

Biehl, J. 2007. "Pharmaceuticalization: AIDS treatment and global health politics." Anthropological Quarterly 80: 1083-1126.

Boston Women's Health Book Collective. 1973. Our Bodies, Ourselves: A Book by and for Women. New York: Simon \& Schuster.

Brown, P. and S. Zavestoski. 2005. Social Movements in Health. Oxford, UK: Blackwell Publishing.

Busfield, J. 2006. "Pills, Power, People: Sociological Understandings of the Pharmaceutical Industry." Sociology 40: 297-314.

—. 2010. "'A Pill for Every Ill': Explaining the Expansion in Medicine Use." Social Science \& Medicine 70: 934-941.

Carlson, R. V., K. M. Boyd, and D. J. Webb. 2004. "The Revision of the Declaration of Helsinki: Past, Present, and Future." British Journal of Clinical Pharmacology 57: 695-713.

Clarke, A., J. Shim, L. Mamo, J. R. Fosket, and J. R. Fishman. 2010. Biomedicalization: Technoscience Health and Illness in the U.S. Duke University Press.

Clarke, A. E., L. Mamo, J. R. Fishman, J. K. Shim, and J. R. Fosket. 2003. "Biomedicalization: Technoscientific Transformations of Health, Illness, and U.S. Biomedicine." American Sociological Review 68: 161-194. 
Conrad, P. 2005. "The Shifting Engines of Medicalization." Journal of Health and Social Behavior 46: 3-14.

Crossley, N. 2006. Contesting Psychiatry: Social Movements in Mental Health. London, UK: Routledge.

Dumit, J. 2012a. Drugs for Life: How Pharmaceutical Companies Define Our Health. Durham, NC: Duke University Press.

—. 2012b. "Prescription Maximization and the Accumulation of Surplus Health in the Pharmaceutical Industry: The_BioMarx_Experiment." In Lively Capital:

Biotechnologies, Ethics, and Governance in Global Markets, edited by K. Sunder Rajan, 45-92. Durham and London: Duke University Press.

Farmer, P. 2003. Pathologies of Power: Health, Human Rights, and the New War on the Poor. Berkeley, CA: University of California Press.

Farmer, P. and N. G. Campos. 2004. "New Malaise: Bioethics and Human Rights in the Global Era." Journal of Law, Medicine \& Ethics 32: 243-251.

Figert, A. E. 2011. "The Consumer Turn in Medicalization: Future Directions with Historical Foundations." In The Handbook of the Sociology of Health, Illness \& Healing: Blueprint for the 21st Century, edited by B. Pescosolido, J. Martin, J. Mcleod, and A. Rogers, 291307. New York: Springer.

Fisher, J. A. 2006. “Co-ordinating 'ethical' clinical trials: the role of research coordinators in the contract research industry.” Sociology of Health \& Illness, 28: 678-694.

Fisher, J.A. 2009. Medical Research for Hire: The Political Economy of Pharmaceutical Clinical Trials. New Brunswick, NJ: Rutgers University Press. 
Gabe, J. and Bury, M. 1988. “Tranquillisers as a Social Problem.” Sociological Review 36: 320352.

Getz, K. A. and J. R. Vogel. 2009. "Successful Outsourcing: Tracking Global CRO Usage." Applied Clinical Trials 18: 42-50.

Glickman, S. W., J. G. McHutchison, E. D. Peterson, C. B. Cairns, R. A. Harrington, R. M. Califf, and K. A. Schulman. 2009. "Ethical and Scientific Implications of the Globalization of Clinical Research." New England Journal of Medicine 360: 816-823.

Gutmann, A. and J. W. Wagner et al. 2011. "Moral Science: Protecting Participants in Human Subjects Research." edited by Presidential Commission for the Study of Bioethical Issues. Washington, DC: U.S. Department of Health and Human Services.

Harris, G. 2013. “Patent’s Defeat in India is Key Victory for Generic Drugs” NYTimes, April 1.

Hartmann, B. 1987. Reproductive Rights and Wrongs: The Global Politics of Population Control and Contraceptive Choice. New York: Harper and Row.

Heimer, C. A. 2012. "Inert Facts and the Illusion of Knowledge: Strategic Uses of Ignorance in HIV Clinics." Economy and Society 41: 17-41.

Hoeyer, K. "Informed Consent: The Making of a Ubiquitous Rule in Medical Practice.” Organization 16:267-288.

Katz, J.1992. 'The Consent Principles of the Nuremberg Code: Its Significance for Then and Now', in G. J. Annas and M. A. Grodin (eds) The Nazi Doctors and the Nuremberg Code, pp. 227-39. Oxford: Oxford University Press.

Lock, M.M. 2004. "Medicalization and the Naturalization of Social Control.” In Encyclopedia of Medical Anthropology; Health and Illness in the World's Cultures, edited by C. W. Ember and M. Ember, 116-124. New York: Kluwer Academic/Plenum. 
Marshall, P. and B. Koenig. 2004. "Accounting for Culture in a Globalized Bioethics." Journal of Law, Medicine \& Ethics 32: 252-266.

Nguyen, V. K. 2005. "Antiretroviral Globalism, Biopolitics, and Therapeutic Citizenship." In Global Assemblages, edited by A. O. and S. J. Collier, 124-144. Malden, MA: Blackwell Publishing.

Nichter, M. 1996 [1989]. "Pharmaceuticals, the Commodification of Health, and the Health Care-Medicine Use Transition." In Anthropology and International Health: Asian Case Studies, Theory and Practice in Medical Anthropology and International Health, edited by M. Nichter and M. Nichter, 265-326. Amsterdam: Gordon and Breach Publishers.

Petryna, A. 2006. "Gloalizing Human Subjects Research." In Global Pharmaceuticals: Ethics, Markets, Practices, edited by A. Petryna, A. Lakoff, and A. Kleinman, 33-60. Durham, NC: Duke University Press.

—. 2007. "Clinical Trials Offshored: On Private Sector Science and Public Health." BioSocieties 2: $21-40$.

—. 2009. When Experiments Travel: Clinical Trials and the Global Search for Human Subjects. Princeton, NJ: Princeton University Press.

—. 2011. "Pharmaceuticals and the Right to Health: Reclaiming Patients and the Evidence Base of New Drugs." Anthropological Quarterly 84: 305-330.

Petryna, A., A. Lakoff, and A. Kleinman. 2006. Global Pharmaceuticals: Ethics, Markets, Practices. Berkeley: University of California.

Petty, J. and C. A. Heimer. 2011. "Extending the Rails: How Research Reshapes Clinics." Social Studies of Science 41: 337-360.

Reverby, S. M. Ed. 2000. Tuskegee's Truths: Rethinking the Tuskegee Syphilis Study. Chapel 
Hill: University of North Carolina Press.

—. 2011. "Editorial: Tuskegee: Could it Happen Again?" Postgraduate Medical Journal 77: 553-555.

Rose, N. and C. Novas. 2005. "Biological Citizenship." In Global Assemblages: Technology, Politics, and Ethics as Anthropological Problems, edited by A. Ong and S. J. Collier, 439-463. City needed: Blackwell.

Shostak, S. 2010. "Marking Populations and Persons at Risk: Molecular Epidemiology and Environmental Health." In Biomedicalization: Technoscience, Health, and Illness in the U.S., edited by A. E. Clarke, L. Mamo, J. R. Fosket, J. R. Fishman, and J. K. Shim, 242262. Durham and London: Duke University Press.

Shuster, E. 1997. "Fifty Years Later: The Significance of the Nuremberg Code." New England Journal of Medicine 337: 1436-1440.

Sunder Rajan, K. 2005. “Subjects of Speculation: Emergent Life Sciences and Market Logics in the United States and India.” American Anthropologist 107: 19-39.

Sunder Rajan, K. 2006. Biocapital: The Constitution of Postgenomic Life. Durham and London: Duke University Press.

Sunder Rajan, K. 2007. "Experimental Values: Indian Clinical Trials and Surplus Health." New Left Review 45: 67-88.

—. 2012. "Pharmaceutical Crises and Questions of Value: Terrains and Logics of Global Therapeutic Politics." The South Atlantic Quarterly 111: 321-346.

Timmermans, S. and M. Berg. 2003. The Gold Standard: The Challenge of Evidence-Based Medicine and Standardization in Health Care. Philadelphia: Temple University Press.

Timmermans, S. and S. Epstein. 2010. "A World of Standards but not a Standard World: Toward 
a Sociology of Standards and Standardization." Annual Review of Sociology 36: 69-89.

Whitmarsh, I. 2008. Biomedical Ambiguity: Race, Asthma, and the Contested Meaning of Genetic Research in the Caribbean. Ithaca and London should you list both cities?: Cornell University Press.

Williams, S. J., J. Gabe, and P. Davis. 2008. "The Sociology of Pharmaceuticals: Progress and Prospects." Sociology of Health \& Illness 30: 813-824.

Williams, S. J., P. Martin, and J. Gabe. 2011. "The Pharmaceuticalization of Society? A Framework for Analysis." Sociology of Health \& Illness 33: 710-725.

Williams, S. J., C. Seale, S. Boden, P. Lowe, and D. L. Steinberg. 2008. "Waking up to Sleepiness: Modafinil, the Media and the Pharmaceuticalisation of Everyday/night Life." Sociology of Health \& Illness 30: 839-855.

Wolinsky, H. 2006. "The Battle of Helsinki " EMBO reports 7: 670-672.

WHO Drug Information v. 19, no. 3 2005, Access to Medicines.

U.S. Presidential Commission for the Study of Bioethical Issues, 2011. MORAL SCIENCE: Protecting Participants in Human Subjects Research, Washington, D.C.(http://www.bioethics.gov).

Zola, I. 1972. "Medicine as an Institution of Social Control." Sociological Review 20: 487-504. 
Notes

${ }^{1}$ According to the Pharmaceutical Research and Manufacturers of America (PHRMA), only “one of every 10,000 potential medicines investigated by America’s research-based pharmaceutical companies makes it through the research and development and is approved for patient use by the United States Food and Drug Administration” and on average it takes 15 years of research and development and more than \$800 million for each pharmaceutical that makes it to the market.

http://www.phrma.org/innovation/ PhRMA “Innovation” Retrieved Sept. 12, 2007

${ }^{2}$ See Trials of War Criminals before the Nuremberg Military Tribunals under Control Council Law No. 10", Vol. 2, pp. 181-182. Washington, D.C.: U.S. Government Printing Office, 1949.

${ }^{3}$ See the World Medical Association for the most current version of the Declaration http://www.wma.net/en/10home/index.html

${ }^{4}$ For example, in Mumbai, India, most of the subjects for clinical trials were recruited from among unemployed textile workers who had lost their jobs after the collapse of the textile industry in the 1980s and 1990s (Sunder Rajan 2005).

${ }^{5}$ The Indian state has just begun to do this by issuing compulsory licenses for producing generic versions of patented medicines (see Harris, NYT April 1, 2013). 